Check for updates

Cite this: RSC Adv., 2019, 9, 39355

\title{
High-efficiency adsorption of tetracycline by the prepared waste collagen fiber-derived porous biochar $\dagger$
}

\begin{abstract}
Xinxing Wei, ${ }^{\text {ac }}$ Renjing Zhang, ${ }^{\text {ac }}$ Wenchao Zhang, ${ }^{\text {ac }}$ Yue Yuan ${ }^{\text {bb }}$ and Bo Lai (D) *ac
Porous biochar (PBC) derived from $\mathrm{Cr}$-containing waste collagen fibers was prepared by two-step pyrolysis to $800{ }^{\circ} \mathrm{C}$ (PBC-800) and alkali activation. Brunauer-Emmet-Teller (BET) analysis, scanning electron microscopy (SEM), Raman spectroscopy, X-ray photoelectron spectroscopy (XPS), Fourier transform infrared spectroscopy (FTIR), X-ray fluorescence (XRF), thermogravimetric analysis (TGA) and zeta potential analysis were used to characterize PBC-800. Batch experiments showed that PBC-800 had an excellent removal effect on tetracycline (TC), and the maximum adsorption capacity was $593.84 \mathrm{mg} \mathrm{g}^{-1}$. Meanwhile, PBC-800 was found to be suitable for a wide $\mathrm{pH}$ range. The isothermal adsorption and kinetic model fitting proved that the TC adsorption by PBC-800 occurred via 5 types of chemical adsorption. The main rate-limiting step was closely related to the initial concentration of TC. The total release of $\mathrm{Cr}$ was less than $0.05 \mathrm{mg} \mathrm{L}^{-1}$, which indicated that PBC-800 was stable and did not cause serious secondary pollution. Compared to the conventional metal-free biomass, $\mathrm{Cr}$ in a waste collagen fiber (WCF) played an important role in carbon formation and adsorption. The excellent adsorption properties of PBC-800 indicated that it could enrich low concentrations of TC in water. Thus, WCF can be used to prepare cost-effective PBC, which supplies a new process to reuse $\mathrm{Cr}$-containing waste.
\end{abstract}

Received 11th September 2019 Accepted 12th November 2019

DOI: 10.1039/c9ra07289f

rsc.li/rsc-advances process is not fully mineralized, it may cause secondary pollution due to the production of more toxic by-products. ${ }^{17}$ On the contrary, adsorption is the primary choice due to its nontoxicity, economic feasibility, and effectiveness; moreover, it does not produce secondary pollution and limits the flow to avoid the spread of pollutants.

Biochar (BC), derived from the pyrolysis of biomass, consists of two parts. One is a highly graphitized black carbon repolymerized by pyrolysis gas, and the other is a coke-type black carbon composed of solid residues. ${ }^{18}$ The structural properties of BC are as follows: it is highly aromatic and porous, has a high specific surface area (SSA) and large pore volume, and is rich in various oxygen-containing functional groups. Agricultural and industrial wastes such as leaves, ${ }^{19}$ rice straw ${ }^{20}$ sawdust, ${ }^{21}$ waste chicken feathers, ${ }^{22}$ sewage sludge, ${ }^{23}$ crab shells, ${ }^{24}$ pecan nutshells, ${ }^{25}$ and WCF are frequently used as BC precursors due to their low prices. ${ }^{26,27}$

The tanning industry has produced a large amount of leather solid waste. Cr-containing waste accounts for about $20 \%$ of the world's total leather waste. ${ }^{28}$ There are nearly 1.4 million tons of waste leather produced every year in China, and the reuse of this resource is very necessary (http://www.chinaleather.org in Chinese). There are few reports on leather waste-derived BC. Kantarli et al. used $\mathrm{CO}_{2}$ physical activation and $\mathrm{H}_{3} \mathrm{PO}_{4}$ and $\mathrm{ZnCl}_{2}$ chemical activation to make leather waste into $\mathrm{BC}$ for the adsorption of toxic pollutants in water. ${ }^{27}$ Oliveira and his companions made waste leather into Cr-containing BC, which 
applied Cr oxide to catalyze the production of a hydroxyl radical degradation dye by hydrogen peroxide. ${ }^{26}$ Currently, there are no studies on the adsorption of antibiotic contaminants by leather collagen fiber-derived BC and the discussion of the adsorption mechanism.

Taking into account the reuse of WCF resources, in this study, potassium hydroxide $(\mathrm{KOH})$ was used as an activator to treat Cr-containing waste leather by a two-step pyrolysis process to produce $\mathrm{PBC}-800$ containing poly-metallic minerals for the rapid and efficient adsorption of TC in an aqueous solution. The purpose of this research was to (1) prepare and characterize PBC-800 and demonstrate the superiority of PBC-800 to others, (2) study the kinetic and isotherm models to understand the adsorption process, (3) explore the effects of anions with various intensities on the PBC-800 adsorption of TC, and (4) determine the mechanism of the adsorption of TC by PBC-800.

\section{Experimental materials and methods}

\subsection{Materials and reagents}

The details of the reagents used in this experiment have been provided in the ESI. $\dagger$

\subsection{Preparation of waste collagen fiber-derived porous biochar}

WCF was crushed by a skin powder crusher into a particle size of about $1 \mathrm{~mm}$ after drying for two days at 50-60 ${ }^{\circ} \mathrm{C}$. Referencing the method described by Konikkara, ${ }^{29} \mathrm{PBC}-800$ was prepared by a two-stage process including pre-carbonization and alkali activator modification. The pre-carbonization process was carried out in the presence of nitrogen, the temperature control program of the tube furnace was set to $400{ }^{\circ} \mathrm{C}$, the heating rate was $5{ }^{\circ} \mathrm{C} \mathrm{min}^{-1}$, and the temperature of $400{ }^{\circ} \mathrm{C}$ was kept for $4 \mathrm{~h}$. The remaining substance at this stage was labeled as BC-400. In the chemical modification process, BC-400 was ultrasonically mixed with a $\mathrm{KOH}$ solution $(3.65 \mathrm{M})$ at a solid-liquid ratio of $1: 4$ until drying to constant weight. After impregnation, the mixture was heated to $800{ }^{\circ} \mathrm{C}$ under anaerobic conditions and incubated for $2 \mathrm{~h}$. After washing several times with hot deionized water for removing the soluble substances and drying, the final carbon material was labeled as PBC-800.

\subsection{Characterizations of material}

Specific methods have been provided in the ESI. $\dagger$

\subsection{Batch experiments}

The adsorption isotherm experiments were carried out by vigorously shaking $100 \mathrm{~mL}$ of TC solution (20 to $220 \mathrm{mg} \mathrm{L}^{-1} \pm$ $\left.5 \mathrm{mg} \mathrm{L}{ }^{-1}, \mathrm{pH}=6\right)$ mixed with $20 \mathrm{mg}( \pm 0.5 \mathrm{mg})$ of PBC-800 to reach equilibrium. The supernatant was filtered using a $0.45 \mu \mathrm{m}$ filter and quantified by a UV spectrophotometer at $365 \mathrm{~nm} .^{30}$

The exploration of adsorption kinetic features requires sampling at different time points. Except for the initial concentration of TC $\left(20 \mathrm{mg} \mathrm{L}^{-1}\right.$ and $\left.100 \mathrm{mg} \mathrm{L}^{-1}, \pm 5 \mathrm{mg} \mathrm{L}^{-1}\right)$, other experimental conditions were consistent with the exploration of isothermal adsorption properties.

In order to understand the applicable $\mathrm{pH}$ of $\mathrm{PBC}-800$, the initial $\mathrm{pH}$ was adjusted to different $\mathrm{pH}$ values using $0.1 \mathrm{M} \mathrm{HCl}$ or $\mathrm{NaOH}$. In addition, to investigate the effects of the different concentrations of various anions on the adsorption of TC, PBC800 was added to the TC solution with various anion concentrations $(1,5,10,20,50 \mathrm{mM})$. The $\mathrm{pH}$ of the system was monitored before and after the reaction. Unless otherwise stated, this experiment was completed at $25{ }^{\circ} \mathrm{C}$.

Three parallel experiments were set up, with a standard deviation of less than $5 \%$, and the arithmetic mean values were calculated. The adsorption capacity at time $t, q_{t},\left(\mathrm{mg} \mathrm{g}^{-1}\right)$ and the removal efficiency (R\%) were determined using eqn (1) and (2):

$$
\begin{gathered}
q_{t}=\frac{\left(C_{0}-C_{t}\right) V}{M_{0}} \\
R=\frac{100\left(C_{0}-C_{t}\right)}{C_{0}}
\end{gathered}
$$

where $C_{0}$ and $C_{t}$ represents the initial TC concentration and TC concentration at reaction time $t$ minutes $\left(\mathrm{mg} \mathrm{L}^{-1}\right)$, respectively, and $M_{0}$ is the quantity of the adsorbent $(\mathrm{mg})$. The isothermal adsorption and kinetic models are listed in Table S1. $\dagger$

\section{Results and discussion}

\subsection{The characteristics of the adsorbent}

3.1.1. Adsorbent structural properties. It is well known that $\mathrm{KOH}$ is a widely used chemical activator. Its activation mechanism includes chemical activation, physical activation and metal potassium intercalation leading to carbon lattice expansion to form porous structures and increase the SSA of PBC. ${ }^{31}$ The following four equations illustrate the activation process of $\mathrm{KOH}:{ }^{32}$

$$
\begin{gathered}
2 \mathrm{KOH}+\mathrm{CO}_{2}=\mathrm{K}_{2} \mathrm{CO}_{3}+\mathrm{H}_{2} \mathrm{O} \uparrow \\
2 \mathrm{C}+2 \mathrm{KOH}=2 \mathrm{CO}_{2} \uparrow+2 \mathrm{~K} \uparrow+\mathrm{H}_{2} \uparrow \\
\mathrm{K}_{2} \mathrm{CO}_{3}+\mathrm{C}=\mathrm{K}_{2} \mathrm{O}+2 \mathrm{CO} \uparrow \\
\mathrm{K}_{2} \mathrm{O}+\mathrm{C}=2 \mathrm{~K} \uparrow+\mathrm{CO} \uparrow
\end{gathered}
$$

The SSA of PBC-800 produced in this experiment reached $2010.4 \mathrm{~m}^{2} \mathrm{~g}^{-1}$, and the total pore volume was $1.2 \mathrm{~cm}^{3} \mathrm{~g}^{-1}$ (Table 1). The mesopore (pore diameter: 2-50 $\mathrm{nm}$ ) volume was approximately $80 \%$ of the total pore volume. Fig. $\mathrm{S} 1 \uparrow$ shows that micropore (pore diameter: $<2 \mathrm{~nm}$ ) filling leads to a sharp rise in nitrogen adsorption during the low-pressure phase. As the relative pressure increased, the nitrogen absorption and desorption curve of PBC-800 showed a mild slope and $\mathrm{a}_{4}$ type hysteresis loop, which indicates that most of the pores of the PBC-800 were slit holes produced by the layered structure. ${ }^{29}$ The average pore diameter calculated by the $\mathrm{BJH}$ method was $2.8 \mathrm{~nm}$, which is larger than the molecular diameter of TC (1.27 $\mathrm{nm}) .{ }^{30}$ Due to smaller size exclusion, it is reasonable to expect 
Table 1 Sample identification, average pore diameter, surface area for BC-400 and PBC-800

\begin{tabular}{|c|c|c|c|c|c|c|c|c|c|}
\hline Sample & $S_{\mathrm{BET}}^{a}\left(\mathrm{~m}^{2} \mathrm{~g}^{-1}\right)$ & $S_{\mathrm{mic}}^{b}\left(\mathrm{~m}^{2} \mathrm{~g}^{-1}\right)$ & $S_{\text {meso }}^{c}\left(\mathrm{~m}^{2} \mathrm{~g}^{-1}\right)$ & $V_{\text {total }}{ }^{d}\left(\mathrm{~cm}^{3} \mathrm{~g}^{-1}\right)$ & $V_{\text {micro }}^{e}\left(\mathrm{~cm}^{3} \mathrm{~g}^{-1}\right)$ & $V_{\text {meso }} f\left(\mathrm{~cm}^{3} \mathrm{~g}^{-1}\right)$ & $V_{\text {micro }} / V_{\text {total }}(\%)$ & $V_{\text {meso }} / V_{\text {total }}(\%)$ & $D_{\mathrm{p}}^{g}(\mathrm{~nm})$ \\
\hline PBC-800 & 2010.4 & 412 & 1599 & 1.2 & 0.2 & 0.9 & 20.2 & 79.8 & 2.8 \\
\hline
\end{tabular}

${ }^{a}$ BET surface area. ${ }^{b}$ Micropore surface area. ${ }^{c}$ Mesopore surface area. ${ }^{d}$ Total pore volume. ${ }^{e}$ Micropore volume. ${ }^{f}$ Mesopore volume. ${ }^{g}$ Average pore diameter, - : no data.

that the PBC-800 has sufficient pore size to allow the TC to permeate the pore interior.

The SEM images of samples are presented in Fig. S2. $\dagger$ WCF (Fig. S2(A) $\dagger$ ) is a unique compact fiber bundle structure with a smooth surface. The surface of BC-400 (Fig. S2(B) $\dagger$ ) does not have a distinct porous structure. Consistent with the analysis of the nitrogen adsorption and desorption, Fig. S2(C) and (D) $\dagger$ clearly show that PBC-800 was etched by lye to produce a rich slit hole, which confirmed that $\mathrm{KOH}$ does play a positive role in the development of pores.

3.1.2. Adsorbent surface chemical composition. The elemental compositions of WCF, BC-400 and PBC-800 are shown in Tables 2 and $\mathrm{S} 2 . \dagger$ As the pyrolysis temperature increased, the $\mathrm{C}$ content gradually increased (33.2\% to $67.1 \%)$, and the $\mathrm{H}(6.2 \%$ to $2.4 \%), \mathrm{N}(12.3 \%$ to $1.8 \%), \mathrm{O}(35.9 \%$ to $9.9 \%)$ and $\mathrm{S}(1.4 \%$ to $0.8 \%)$ contents decreased rapidly. The $\mathrm{H} / \mathrm{C}$ ratio represents aromaticity, and the $(\mathrm{O}+\mathrm{N}) / \mathrm{C}$ ratio means polarity. ${ }^{33}$ Thus, the aromaticity of PBC-800 was strengthened ( 0.187 to $0.036)$ and the polarity was greatly reduced (1.4 to 0.18 ). The literature documents a high adsorption capacity for chlortetracycline because the reduction in the $\mathrm{H} / \mathrm{C}$ and $(\mathrm{O}+\mathrm{N}) / \mathrm{C}$ ratio made the BC surface more hydrophobic. ${ }^{34}$ WCF contains more metallic elements owing to the complexity of the tanning process. Semi-quantitative determination of the presence of multiple metals on the adsorbent was carried out using XRF and the $\mathrm{Cr}$ content was the largest (Table S2 $\dagger$ ). General biomass, such as leaf, straw and sawdust derived-BC, does not contain metallic elements. The BC was modified by adding ferric and zinc ions to achieve great adsorption properties for pollutants. ${ }^{21}$ Conversely, PBC-800 did not require the addition of metalcontaining chemical activators to achieve those properties.

The XRD analysis of BC-400 and PBC-800 are shown in Fig. 1(A). The main components of the crystals contained in BC400 were $\mathrm{Cr}$ oxide, copper blue, and $\mathrm{Cr}$ carbide. After activation by $\mathrm{KOH}, \mathrm{Cr}$ carbonyl and graphite peaks appeared in PBC-800 at

Table 2 Basic elemental composition of WCF, BC-400 and PBC-800

Basic elemental composition $^{a}$

\begin{tabular}{lrrrrrrl}
\cline { 2 - 6 } Adsorbent & $\mathrm{C} \%$ & $\mathrm{H} \%$ & $\mathrm{~N} \%$ & $\mathrm{O} \%$ & \multicolumn{1}{c}{$\mathrm{S} \%$} & \multicolumn{1}{c}{$\mathrm{H} / \mathrm{C}$} & $(\mathrm{O}+\mathrm{N}) / \mathrm{C}$ \\
\hline WCF & 33.2 & 6.2 & 12.3 & 35.9 & 1.4 & 0.187 & 1.4 \\
BC-400 & 49.9 & 4.3 & 11.2 & 20.3 & 1.1 & 0.086 & 0.6 \\
PBC-800 & 67.1 & 2.4 & 1.8 & 9.9 & 0.8 & 0.036 & 0.18
\end{tabular}

${ }^{a}$ Determined by elemental analyzer. $26^{\circ}, 44^{\circ}, 55^{\circ}$, and $64^{\circ}$ corresponding to the (002), (100/101), (004) and (221) planes of the graphite structure. ${ }^{35,36}$ The graphite peak was weak, which may have been affected by $\mathrm{Cr}$ compounds. It has been reported that $\mathrm{Cr}\left(\mathrm{NO}_{3}\right)_{3}$ was used as a catalyst to promote the graphitization of carbon under microwave irradiation. ${ }^{36}$ Thus, $\mathrm{Cr}$ in the WCF can also be active in the carbon formation process, making the degree of graphitization of PBC-800 higher than that of BC-400 under hightemperature conditions.

As shown by the Raman spectrum (Fig. 1(B)), the D-band (1341-1360 $\left.\mathrm{cm}^{-1}\right)$, G-band (1563-1589 $\mathrm{cm}^{-1}$ ) and $\mathrm{G}^{\prime}$-band (2780-2851 $\left.\mathrm{cm}^{-1}\right)$ are fundamental bands in Raman spectroscopy for graphite material. ${ }^{36}$ The $\mathrm{D}$ peak corresponds to the vibration of the edge plane in the $\mathrm{sp}^{3}$ carbon lattice, which was activated by defective disordered carbon. ${ }^{29}$ The $\mathrm{G}$ peak was produced by the tensile bonding of all defect-free carbon rings and $\mathrm{sp}^{2}$ heteroatoms on the carbon chain, representing graphite carbon. ${ }^{29} \mathrm{G}^{\prime}$ directs the graphite overtone peak of the $\mathrm{sp}^{2}$ bonded planar graphene sheet stack response. ${ }^{37}$ It is apparent that the $\mathrm{G}^{\prime}$ intensity of PBC-800 was enhanced and it has also been reported that the embedding of metal has a significant effect on $\mathrm{G}^{\prime}{ }^{37}$ "I" represents the intensity of the peak band, and the intensity ratio $\left(I_{\mathrm{D}} / I_{\mathrm{G}}\right)$ reflects the degree of graphitization and disorder of $\mathrm{BC}^{29}$ The $I_{\mathrm{D}} / I_{\mathrm{G}}$ (intensity ratio) of BC-400 and PBC-800 were 1.71 and 1.32 (Fig. 1(C) and (D)), respectively, which demonstrated that the surface activation process increased the size of the $\mathrm{sp}^{2}$ conjugated system and reduced the disorder of $\mathrm{PBC}-800^{36}$.

\subsection{Control experiment}

To demonstrate the necessity of a two-step pyrolysis, one-step pyrolysis was used to prepare $\mathrm{BC}$ at different temperatures (BC-400, BC-600 and BC-800). Although the adsorption capacity increased slightly with increasing the pyrolysis temperature, the removal efficiency was less than $20 \%$ (Fig. S3†); therefore, it was suitable for preparing PBC by a two-step pyrolysis method. The adsorption of TC by PBC (PBC-600 and PBC-800) of different activation temperatures was investigated. It is obvious that PBC600 only reached $25 \%$ and PBC- 800 could attain $99 \%$ in terms of the TC adsorption efficiency, which reflected the importance of pyrolysis to $800{ }^{\circ} \mathrm{C}$ in the activation step.

In order to indirectly prove the action of $\mathrm{Cr}$, the adsorbent was prepared using Cr-free WCF (commonly known as white skin powder). BC-400-W, PBC-600-W and PBC-800-W (W means white) were prepared according to the method described in Section 2. The removal efficiencies of PBC-600-W and PBC-800- 

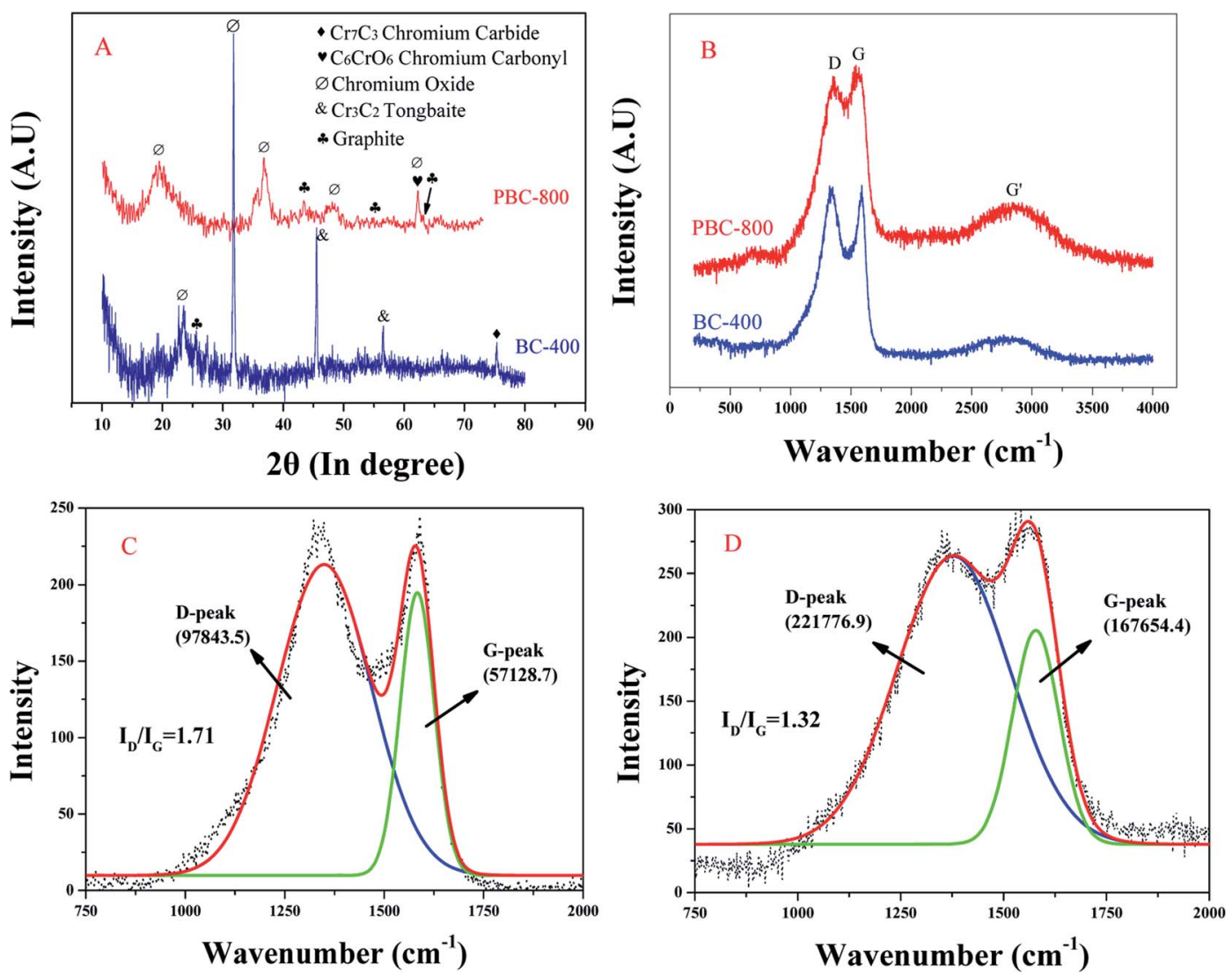

Fig. 1 XRD patterns (A) and Raman spectra (B) of samples. Peak fitting of BC-400 (C) and PBC-800 (D) Raman spectra.

W were just half of PBC-600 and PBC-800, which indicated that Cr may play a role in carbon formation and adsorption processes. Cr may undergo activation during carbon formation and can combine with TC through surface complexation (SC) and cation bridges (CB).

BC-400-W and $\mathrm{Cr}_{2} \mathrm{O}_{3}$ were mixed in a ratio of $20: 1$ and the PBC-800-Mix was prepared by $\mathrm{KOH}$ activation. As shown in the XRD diagram (Fig. S4 $\dagger$ ), the PBC-800-Mix has only the peak of graphite and $\mathrm{Cr}$ oxide with little intensity. From the aspect of adsorption, the removal efficiency of PBC-800-Mix on TC was obviously lower than that of PBC-800, and also slightly lower than PBC-800-W. The above results may indicate that the extra added $\mathrm{Cr}$ does not significantly promote graphitization in carbon formation, and may also inhibit the PBC-800-Mix adsorption of TC due to the plugging of pore sites. Thus, the uniform and tightly bound nature of trivalent Cr may play an irreplaceable role in carbon formation, which reflects the superiority of WCF as biomass. Table 3 compares the SSA of different biomass-derived $\mathrm{BC}$ with the adsorption amount of TC.

As can be seen from Fig. S5, $\uparrow$ the SSA of PBC-600 after the TC adsorption was significantly smaller than before, which indicated that TC was attached to PBC-600 and occupied an effective site, resulting in the SSA decreasing from $693 \mathrm{~m}^{2} \mathrm{~g}^{-1}$ to $631 \mathrm{~m}^{2}$ $\mathrm{g}^{-1}$. Fig. S2 $\uparrow$ shows the XPS spectrum of Cr $2 \mathrm{p}$ on the surface of PBC- 600 before and after TC adsorption. Since Cr on the surface of PBC-600 reacted with TC, the binding energy of $\mathrm{Cr} 2 \mathrm{p}$ increased from $586.1 \mathrm{eV}$ and $576.32 \mathrm{eV}$ to $586.24 \mathrm{eV}$ and

Table 3 Comparison of the specific surface areas of different biomass-derived BC and adsorption capacity of TC

\begin{tabular}{lllll}
\hline Biomass & Activator & BET $\left(\mathrm{m}^{2} \mathrm{~g}^{-1}\right)$ & $\begin{array}{l}\text { Total pore volume } \\
\left(\mathrm{cm}^{3} \mathrm{~g}^{-1}\right)\end{array}$ & $q_{\text {max }}\left(\mathrm{mg} \mathrm{g}^{-1}\right)$ \\
\hline Rice-husk & $\mathrm{H}_{2} \mathrm{SO}_{4}, \mathrm{KOH}$ & $46.8,117.8$ & $0.033,0.073$ & $23.26,58.82$ \\
Nut shells & $\mathrm{NaOH}_{\text {References }}$ & 1524 & 0.180 & 455.8 \\
Leave & $\mathrm{ZnCl}_{2}$ & 461.98 & 0.3359 & 146.68 \\
Sawdust & $\mathrm{ZnCl}_{2}, \mathrm{FeCl}_{3}$ & 518.54 & 0.069 & 102 \\
Chicken feather & $\mathrm{KOH}$ & $\mathbf{1 8 3 8}$ & 1.033 & 388.33 \\
WCF & KOH & $\mathbf{2 0 1 0 . 4}$ & $\mathbf{1 . 2}$ & $\mathbf{5 9 3 . 8 4}$
\end{tabular}


$576.4 \mathrm{eV}$. The above results indicate that both SSA and surface metal Cr play a certain role when PBC-600 adsorbs TC. However, the effect of PBC-600 on TC adsorption was significantly lower than that of PBC-800, which may be caused by the following. The lower pyrolysis temperature caused more oxygencontaining functional groups to be present in PBC-600 as compared PBC-800. According to the literature, ${ }^{33}$ the pyrolysis temperature affected the hydrophobicity of the biochar. PBC600 has a large polarity index and a small aromatic index, which makes it less hydrophobic than PBC-800. The small hydrophobicity is not conducive to the adsorption of TC.

\subsection{Batch experiments}

3.3.1. Batch equilibrium sorption isotherms. Langmuir, Freundlich, Temkin, Sips and Toth ${ }^{33,38,39}$ were used to fit the test data and the isotherm constants are shown in Fig. 2. The correlation constants $\left(R^{2}\right)$ of the fitted isothermal models were higher than 0.93, except for the Temkin and Freundlich models. The Langmuir equation described homogeneous single-layer adsorption with a maximum adsorption capacity of $593.84 \mathrm{mg}$ $\mathrm{g}^{-1} \cdot{ }^{38}$ The separation factor $\left(R_{\mathrm{L}}=1 /\left(1+K_{\mathrm{L}} C_{0}\right)\right)$ values were 0.0156 to 0.0026 , which suggest that the adsorption of TC onto PBC-800 was nearly irreversible. ${ }^{30}$ Sips and Toth are threeparameter forms of the Langmuir equation, which introduce the adsorption energy parameter $\gamma$ and the heterogeneity parameter $N_{\mathrm{T}}$, respectively. ${ }^{38,39}$ The values of $\gamma$ and $N_{\mathrm{T}}$ are close to 1 , which indicates that the surface energy of the adsorbent is uniform and the heterogeneity is weak. ${ }^{38,39}$ In this experiment, $\gamma$ and $N_{\mathrm{T}}$ are 0.73 and 0.66 , which signify that the system has the following two advantages. (a) The energy heterogeneity on 8PBC is produced by specific active sites on the surface, which are derived from multiple metal (i.e., $\mathrm{Cr}$ and $\mathrm{K}$ ) intercalation. (b) The degree of heterogeneous monolayer adsorption in the system is close to half. ${ }^{38,39}$ The $q_{\mathrm{m}}$ values fitted by Langmuir, Sips, and Toth are similar and relatively high, and it was expected that the most of the contribution should be due to the high SSA, multiple functional groups and special metal sites of PBC-800.

The $R^{2}$ of the Temkin and Freundlich fits were 0.895 and 0.847. It was shown that the fitting effect of the Temkin equation was slightly higher as compared to Freundlich. The value of $B_{\mathrm{T}}$ was $36.45>1$, which demonstrated that the exothermic reaction was due to electrostatic attraction (EA) and heterogeneous pores. ${ }^{30}$

3.3.2. Batch equilibrium sorption kinetics. The fitting of kinetic models is a practical method for recognizing the adsorption mechanism and the rate-limiting step. The detailed descriptions of the model equations and parameters are shown in Tables S1 and S4. $\uparrow$ TC removed by PBC-800 with different initial concentrations is presented in Fig. 3(A-E).

It is noteworthy that whether the initial concentration was $20 \mathrm{mg} \mathrm{L}^{-1}$ or $100 \mathrm{mg} \mathrm{L}^{-1}$, the Elovich (E) $\left(R^{2}: 0.97937\right.$ and 0.95193 ) model better describes the process of uptake than the pseudo-first-order (PFO) $\left(R^{2}: 0.8236\right.$ and 0.50305) and pseudosecond-order (PSO) $\left(R^{2}: 0.93971\right.$ and 0.72397$)$ models. The hypothesis of the $\mathrm{E}$ model is that the process was energetically

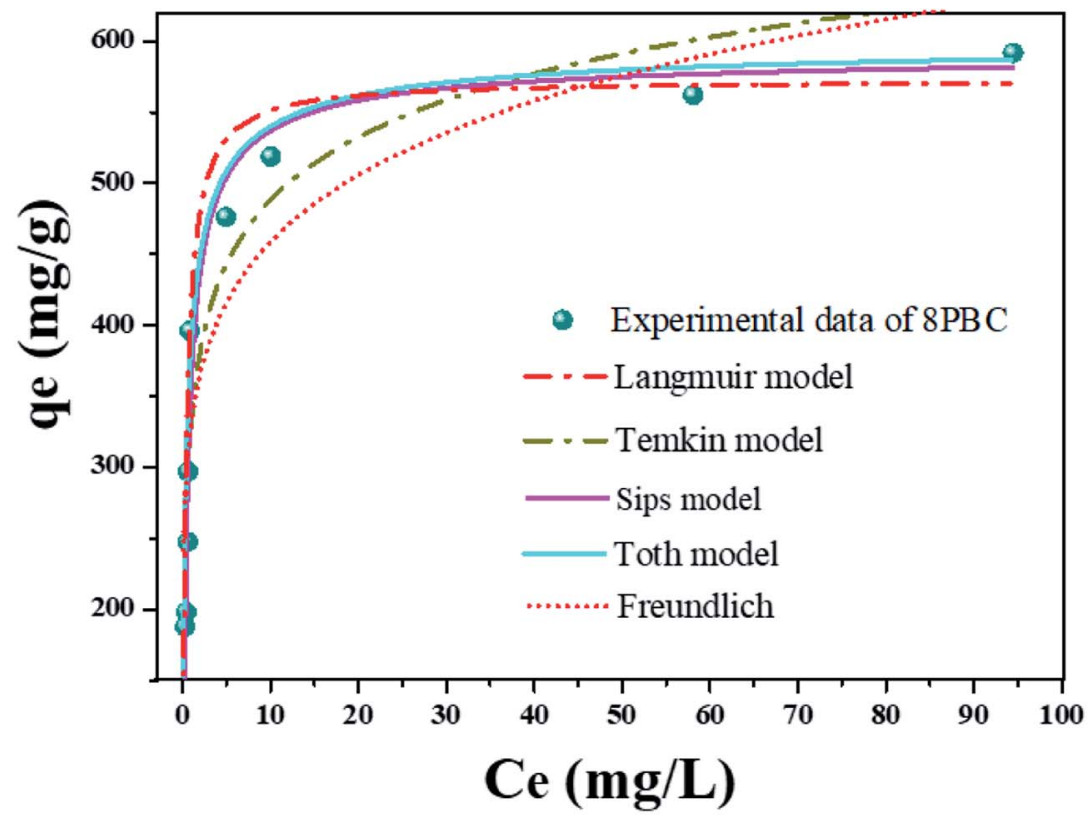

\begin{tabular}{ccccc}
\hline Langmuir & Temkin & Sips & Toth & Freundlich \\
\hline $\mathrm{Q}_{\mathrm{m}}=593.84$ & $\mathrm{~K}_{\mathrm{T}}=230.41$ & $\mathrm{Q}_{\mathrm{m}}=596.36$ & $\mathrm{Q}_{\mathrm{m}}=601.42$ & $\mathrm{~K}_{\mathrm{f}}=330.31$ \\
$\mathrm{~K}_{\mathrm{L}}=1.80$ & $\mathrm{~B}_{\mathrm{T}}=36.45$ & $\mathrm{~K}_{\mathrm{S}}=2.25, \gamma=0.73$ & $\mathrm{~b}_{\mathrm{T}}=5.14, \mathrm{~N}_{\mathrm{T}}=0.66$ & $\mathrm{n}=7.07$ \\
$\mathrm{R}^{2}=0.969$ & $\mathrm{R}^{2}=0.895$ & $\mathrm{R}^{2}=0.974$ & $\mathrm{R}^{2}=0.977$ & $\mathrm{R}^{2}=0.847$
\end{tabular}

Fig. 2 TC sorption isotherms for PBC-800. 

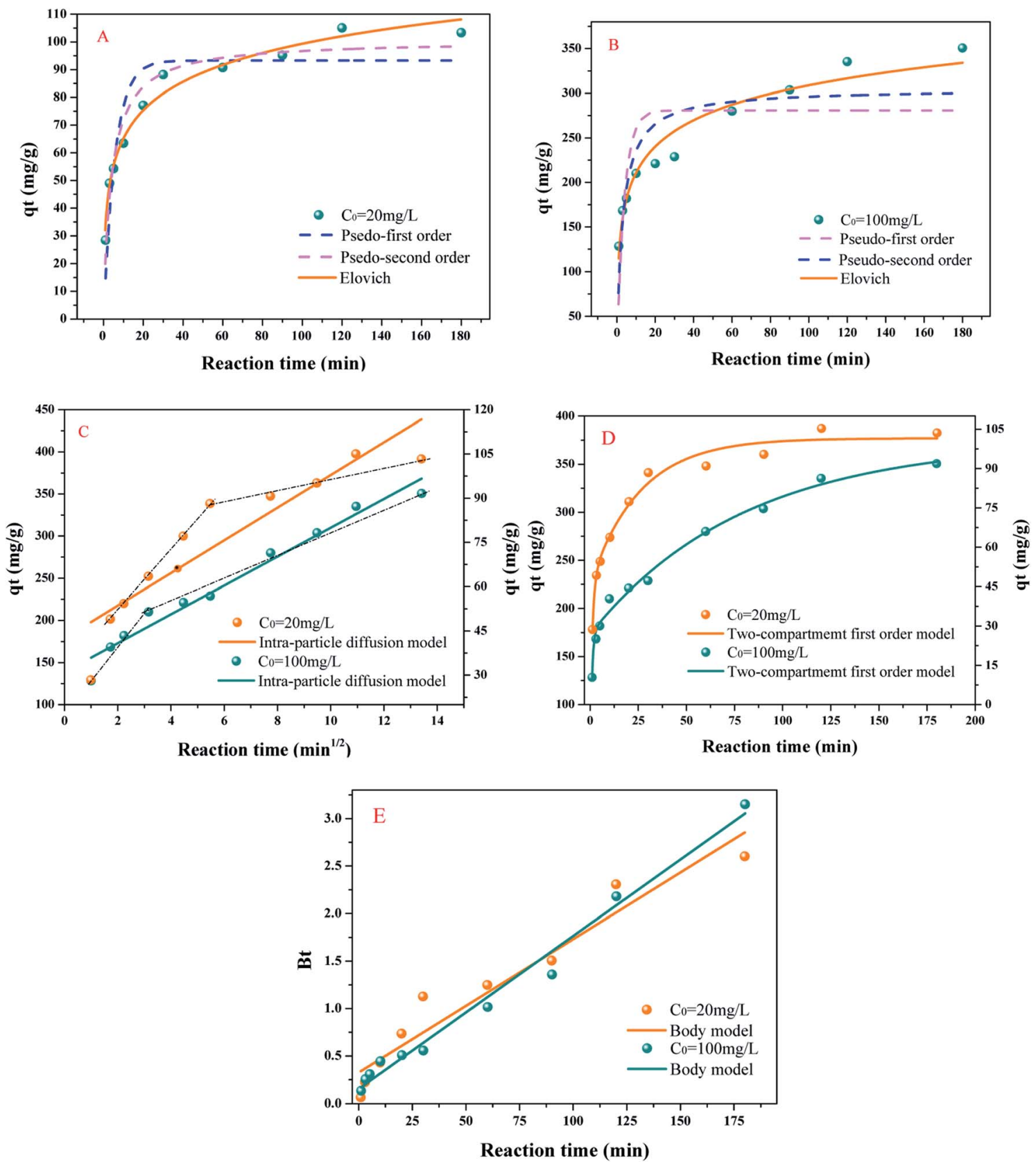

Fig. 3 Kinetic data of TC adsorption on 8PBC (initial concentration is $20 \mathrm{mg} \mathrm{L}^{-1}$ and $100 \mathrm{mg} \mathrm{L}^{-1}$ ). Fitting the pseudo-first-order, pseudo-secondorder, and Elovich models (A and B), intra-particle diffusion model (C), two-compartment first-order model (D), body model (E).

heterogeneous and there was non-desorption. ${ }^{21}$ Thus, it was proved that the chemical adsorption of TC by PBC-800 mainly covered hydrogen bonding (HB), $\pi-\pi$ electron-donor-acceptor $(\pi-\pi$ EDA $)$, and EA. ${ }^{33,40}$

The two-compartment first-order (TFO) model describes the time course of the PBC-800 adsorption of TC (Fig. 3(D)). The high $R^{2}$ value $\left(R^{2}>0.98\right)$ indicated that PBC-800 adsorption of TC was a dual-domain process. ${ }^{21}$ The values of $F_{\mathrm{f}}(0.45827$ and $0.46431)$ were lower than $F_{\mathrm{S}}(0.54173$ and 0.53569$)$. The results revealed that the amount of rapid adsorption was lower than that of slow adsorption, which indicated that slow adsorption was dominant. Zhou et al. considered that rapid adsorption occurred due to HB and $\pi-\pi$ EDA. ${ }^{21}$ The fast adsorption phase may also involve physical adsorption (van der Waals forces) because of the large SSA.

The intra-particle diffusion (IPD) and Boyd model were employed to analyze the actual rate-controlling step (Fig. 3(C) and (E)). A plot of $q_{t}$ versus $t^{0.5}$ displayed several linearities in distinct regions prior to equilibrium. The first stage was rapid adsorption, and the rate-limiting step was liquid film diffusion (LFD). This process is attributed to TC being stacked on the outer surface of PBC-800 ${ }^{30}$. The second stage was slow adsorption, and the rate-limiting step was IPD. TC diffused into the pore interior, ${ }^{30}$ which is similar to the results of Zhou et al. ${ }^{41}$ 
The intercept value represents the thickness of the boundary layer (Fig. 3(C)). When the initial concentrations were $20 \mathrm{mg} \mathrm{L}^{-1}$ and $100 \mathrm{mg} \mathrm{L}^{-1}$, the fitted value of $\mathrm{L}$ was $42.4 \mathrm{mg} \mathrm{g}^{-1}$ and $138.7 \mathrm{mg} \mathrm{g}^{-1}$, and the time of entering the inner diffusion was $30 \mathrm{~min}$ and $9 \mathrm{~min}$. A larger L meant a thicker boundary layer and indicated that the TC entered the internal diffusion phase early. A previous study has shown that the p-interaction of the benzene ring caused the adsorbed molecules to be parallel to each other. ${ }^{42}$ Therefore, plenty of parallel TC molecules were deposited on the surface of PBC-800 at a high concentration, which is advantageous for diffusing TC into the interior of PBC$800^{43}$.

The Body model shows the linear relationship of $B_{t} v s$. time (Fig. 3(E)). The calculation method for $B_{t}$ is recorded in the literature. ${ }^{44}$ The intercept of low concentration $\left(20 \mathrm{mg} \mathrm{L}^{-1}\right)$ was obviously not zero, indicating that LFD dominated. ${ }^{41}$ In contrast, the intercept of high concentration $\left(100 \mathrm{mg} \mathrm{L}^{-1}\right)$ was infinitely close to zero, indicating that the sorption was governed by IPD. ${ }^{41}$ This result coincides with the analysis of IPD.

3.3.3. Effect of initial $\mathbf{p H}$. The adsorption process was reported to depend on the PBC-800 surface charge and TC species, which are critically influenced by the solution $\mathrm{pH}^{45,46}$ The effects of PBC-800 zeta potential and initial $\mathrm{pH}$ on the TC adsorption of BC-400 and PBC-800 were investigated (Fig. 4). The negative zeta potential indicates that electrons are always present regardless of whether the $\mathrm{pH}$ is acidic, neutral or alkaline. At $\mathrm{pH}=6$, the removal efficiency of TC is significant, the adsorption capacity is $105 \mathrm{mg}^{-1}$. Under strong acid conditions, the dominant species of TC was $\mathrm{TCH}_{3}{ }^{+}$in solution. Thus, electrostatic strengthening decreased the barrier of TC molecular diffusion and the adsorption efficiency increased slightly. Once the strong base $\mathrm{NaOH}$ was added to the system and solution $\mathrm{pH}>7$, the major species of TC gradually changed to $\mathrm{TCH}^{-}$and $\mathrm{TC}^{2-}$. The existence of high concentrations of base increased the negative charge of the PBC-800 surface band and electrostatic repulsion caused a weakening of the adsorption efficiency.

Surprisingly, when the $\mathrm{pH}$ gradually increased, the adsorption efficiency of PBC-800 on TC was not reduced all the time. When the $\mathrm{pH}>11$, the main form of $\mathrm{TC}$ is $\mathrm{TC}^{2-}$ and the adsorption efficiency was strengthened because deprotonated nitrogen and negatively charged hydroxyl groups caused strong chelation of TC with polyvalent metal cations. ${ }^{47}$ Mitscher and Martin reported the complexation of antibiotics with $\mathrm{Ca}$, in which the divalent anion complex constants of oxytetracycline (OTC), tetracycline (TET) and chlortetracycline (CTC) were an order of magnitude larger than the monovalent anion complexation constant. ${ }^{48,49}$ Therefore, the reason the adsorption capacity does not decrease all the time under alkaline conditions may be that the strengthening of the metal complex partially offset the effect of electrostatic repulsion and occupied the dominant adsorption at high $\mathrm{pH}$ conditions, which is in line with the mechanism of $\mathrm{BC}$ adsorption of $\mathrm{TC}$ as summarized by Peiris. ${ }^{40}$

Although the change in $\mathrm{pH}$ affected the adsorption capacity of the PBC-800, the PBC-800 still exhibited excellent adsorption capacity (Fig. 4(A)). This is evidence that PBC-800 has applicability under a wide range of $\mathrm{pH}$ conditions and is different from other BC that were poorly adsorbed under per-acid and high alkaline conditions 33 . The stability and possible secondary pollution of PBC- 800 were evaluated by measuring the total $\mathrm{Cr}$ concentration after the reaction. Regardless of acidic or alkaline, the total $\mathrm{Cr}$ concentration was less than $0.05 \mathrm{mg} \mathrm{L}^{-1}$ and within the safe range (WHO Guidelines for Drinking Water Quality, https://www.who.int/zh). There was almost no $\mathrm{Cr}^{6+}$ in the total $\mathrm{Cr}$ ions released during the adsorption process. Studies have shown that the formation of $\mathrm{Cr}$ carbide does not lead to the leaching of $\mathrm{Cr} .^{50}$ Leaching of $\mathrm{Cr}$ ions was significantly reduced $\left(C_{\mathrm{Cr}}<0.01 \mathrm{mg} \mathrm{L}^{-1}\right)$ when the $\mathrm{pH}$ of the experimental condition was neutral. The comprehensive experimental results and actual conditions proved that PBC-800 is very stable at $\mathrm{pH}>3$. It could be applied to wastewater treatment because the $\mathrm{pH}$ of the operating conditions of a typical sewage treatment plant is 5.58.0..$^{51}$

3.3.4. Effect of coexisting anion. In exploring the effects of various anions and ionic strengths on the adsorption of TC by PBC-800, the effects of different concentration gradients and different anions on the adsorption of TC by PBC- 800 were studied. The results are shown in Fig. 5, where the pH of the TC solution was monitored before and after adsorption, and the
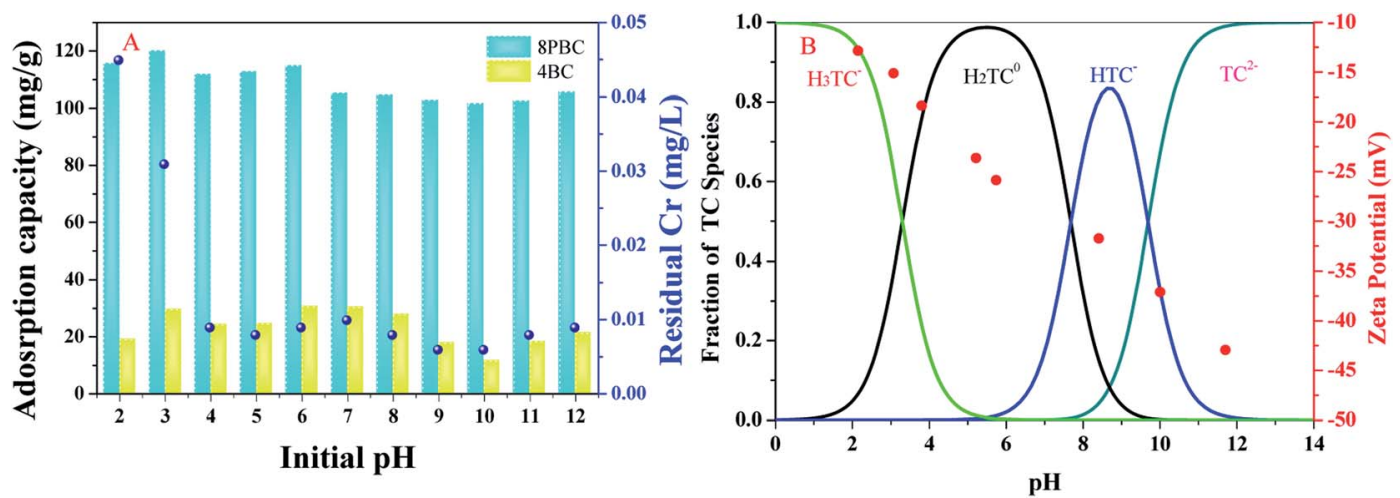

Fig. 4 The effects of initial $\mathrm{pH}$ on the adsorption of TC by PBC- 800 and $\mathrm{BC}-400$ and the concentration of residual $\mathrm{Cr}$ leached after adsorption of TC by PBC- 800 at different $\mathrm{pH}$ (A), species distribution of TC at different $\mathrm{pH}$ and zeta potentials of PBC-800 (B). 

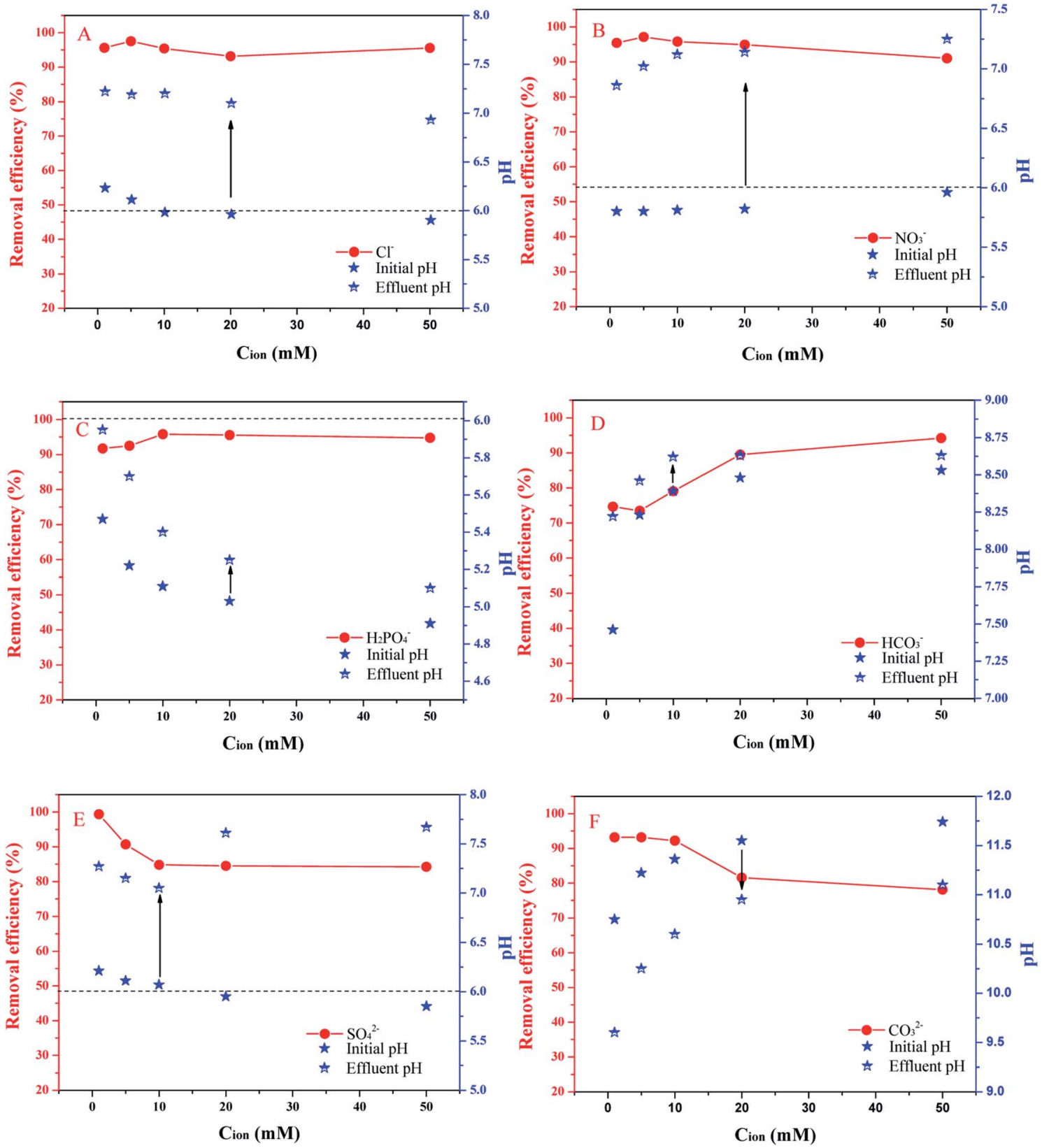

Fig. 5 The effects of coexisting anions $\left(\mathrm{Cl}^{-}, \mathrm{NO}_{3}{ }^{-}, \mathrm{H}_{2} \mathrm{PO}_{4}{ }^{-}, \mathrm{HCO}_{3}{ }^{-}, \mathrm{SO}_{4}{ }^{2-}, \mathrm{CO}_{3}{ }^{2-}\right)$ of various concentrations $(1,5,10,20,50 \mathrm{mM})$ on the adsorption of TC by PBC-800 and pH changes before and after the reaction.

dotted line is the $\mathrm{pH}$ of the TC solution when no anions were added.

Monovalent anions have a slight influence on the adsorption efficiency of TC, except for $\mathrm{HCO}_{3}{ }^{-}$. Anions such as $\mathrm{Cl}^{-}, \mathrm{NO}_{3}{ }^{-}$ and $\mathrm{H}_{2} \mathrm{PO}_{4}{ }^{-}$had a certain promoting effect at concentrations of 1-5 mM, 1-5 mM and 1-10 mM, respectively. Subsequent, increases in the ion concentration slightly inhibited adsorption. The promotion or inhibition of ions on $\mathrm{BC}$ adsorption of organic matter is attributed to the "salting out" effect and the "squeeze-out" effect on carbonaceous adsorbents. ${ }^{52}$ Salt ions influence the structure, electrostatic nature and hydrophobicity of antibiotics, reducing the solubility of antibiotics and increasing the adsorption of antibiotics ("salting out")..$^{52}$ It has been reported that ions can penetrate into the diffusion layer of the graphene surface and eliminate the repulsive force between the adsorbents, which may promote the formation of a more compact aggregate structure. This squeeze-out effect is unfavorable for the uptake of organic matter. ${ }^{53}$ The $\mathrm{pH}$ of the effluent increased because TC was adsorbed by PBC-800. In the presence of $\mathrm{H}_{2} \mathrm{PO}_{4}{ }^{-}$, the $\mathrm{pH}$ was relatively small because $\mathrm{H}_{2} \mathrm{PO}_{4}{ }^{-}$can be ionized to be acidic.

$\mathrm{HCO}_{3}{ }^{-}$has an inhibitory effect on TC adsorption. When the concentration of $\mathrm{HCO}_{3}{ }^{-}$was greater than $5 \mathrm{mM}$, the inhibitory effect was weakened constantly. The main 

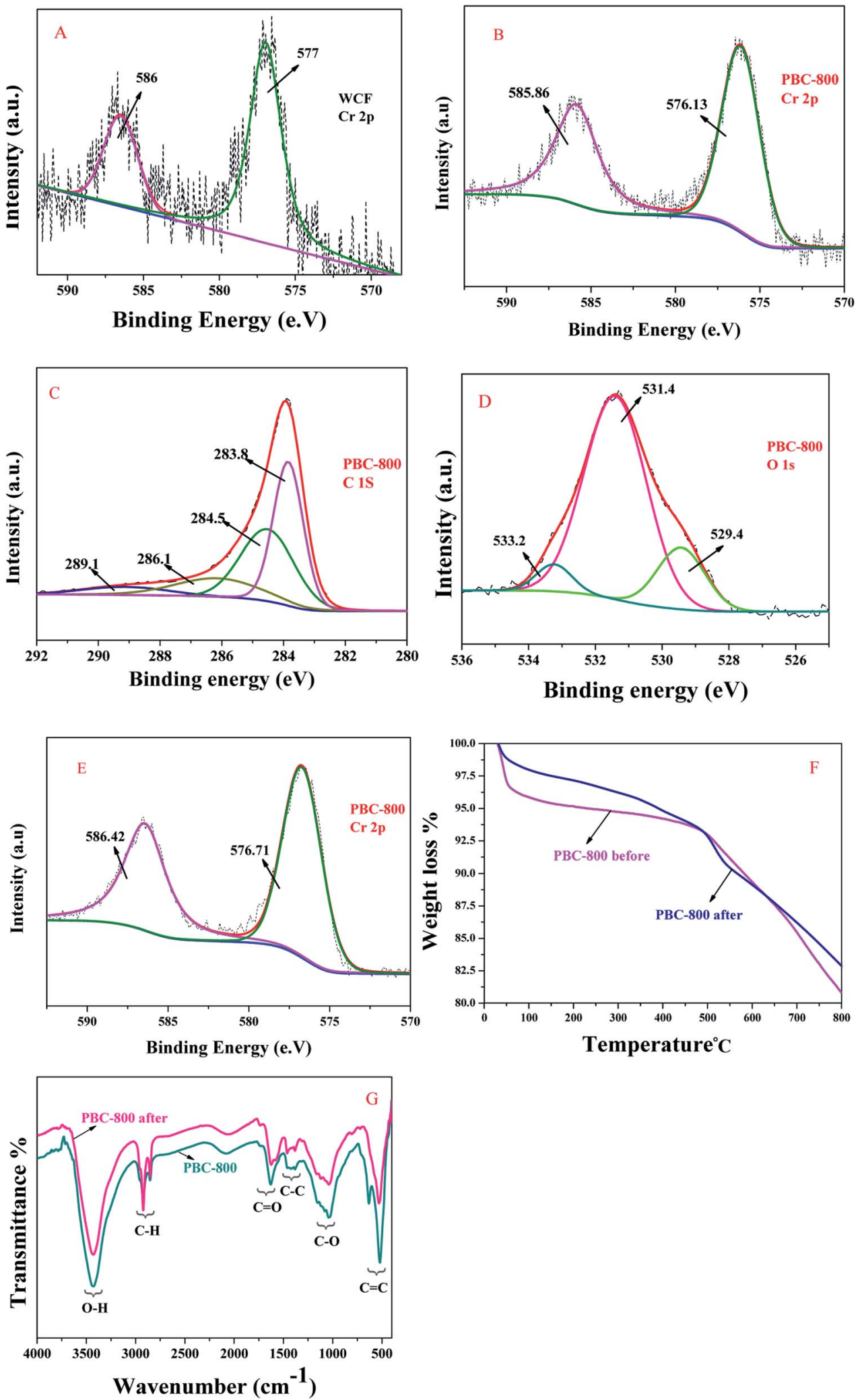

Fig. 6 XPS spectra of WCF (A: Cr 2p) and PBC-800 (B: Cr 2p, C: C 1s, D: O 1s, E: Cr 2p after TC adsorption), thermogravimetric curves (F) and infrared spectra (G) of PBC-800 before and after TC adsorption.

mechanisms of the adsorption process are SC and $\mathrm{CB}$ under alkaline condition. ${ }^{40}$ It has been proved that the effect of electrostatic repulsion is weakened even though the main form of $\mathrm{TC}$ is $\mathrm{HTC}^{-}$. The reason for the slight change in the $\mathrm{pH}$ of the effluent is that $\mathrm{HCO}_{3}{ }^{-}$can be hydrolyzed and ionized. 


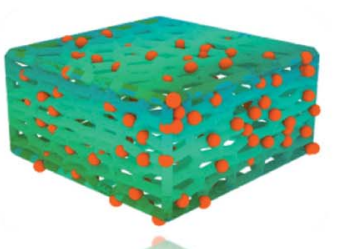

8PBC carbon skeleton with $\mathrm{M}^{\mathrm{n}+}$

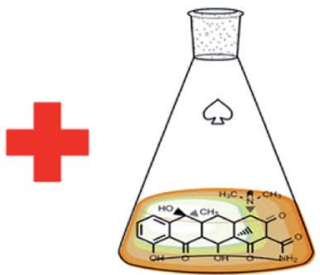

TC solution

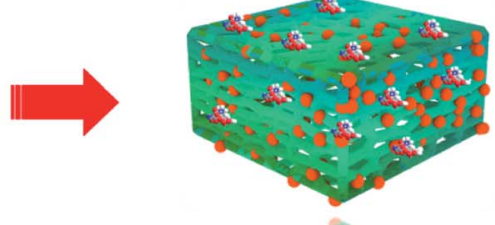

8PBC-loaded TC

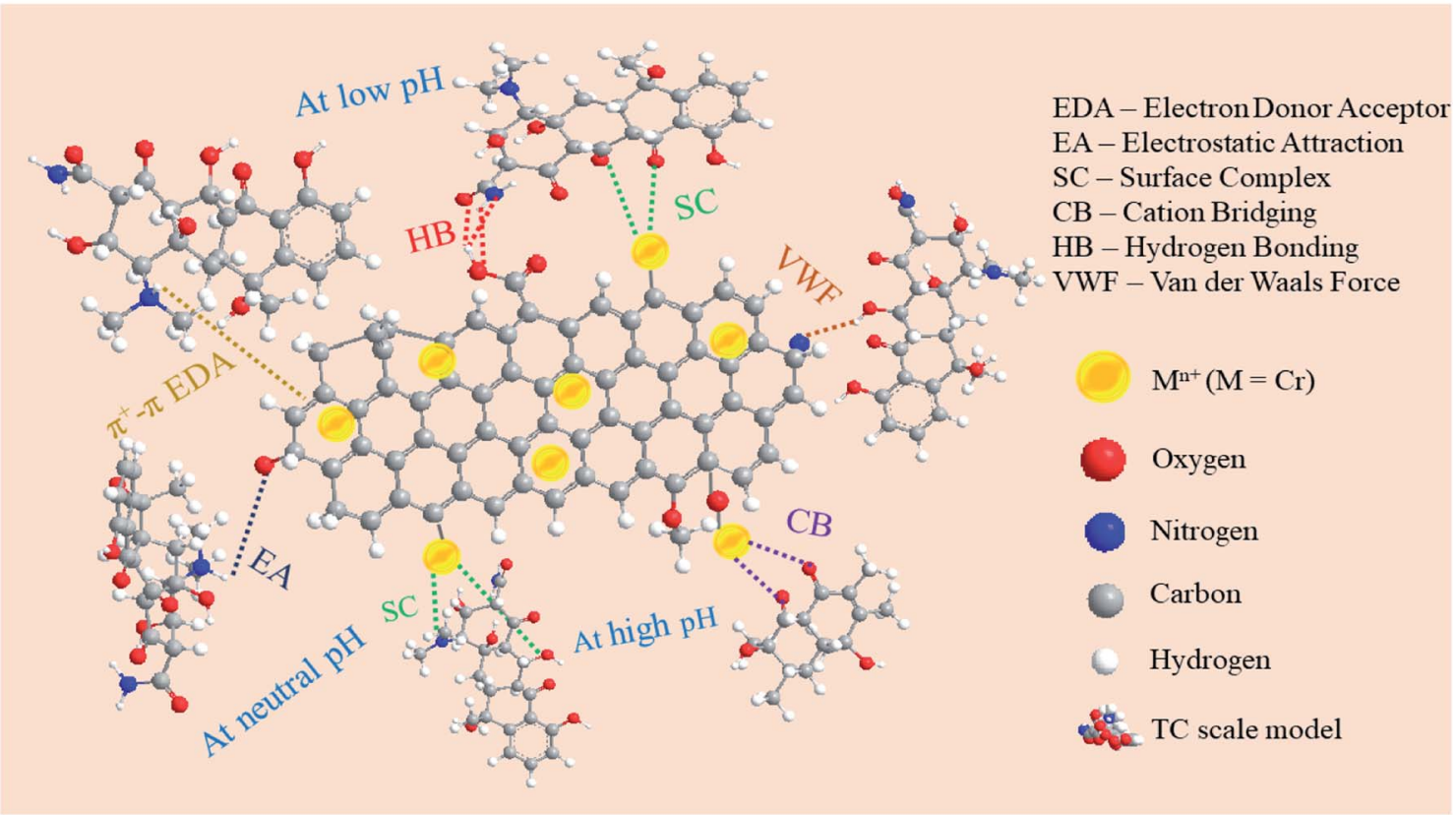

Fig. 7 Graphical illustration of the adsorption mechanisms during the adsorption of TC on the PBC-800 surface.

The presence of $\mathrm{SO}_{4}{ }^{2-}$ and $\mathrm{CO}_{3}{ }^{2-}$ inhibited the adsorption of $\mathrm{TC}$ and the adsorption efficiency was only $80 \%$ because plenty of the adsorption sites were occupied. It has been reported that $\mathrm{Na}^{+}$and $\mathrm{Cl}^{-}$can weaken electrostatic interactions between BC and TC, which resulted in electrostatic shielding. ${ }^{54}$ Thus, the electrostatic shielding of the PBC-800 surface is stronger due to the enhancement of ionic strength.

The different anions at different concentrations have various influences. The ion composition of the actual water body is complex, which means exploring the importance of different ions on the adsorption effect of TC.

\section{Mechanism analysis}

\subsection{Adsorbent functional group}

The XPS of the materials are shown in Fig. 6(A-E). A and B diagrams represent the Cr 2p XPS spectrum of WCF and PBC800 , respectively. Peaks at 586, 577, 585.86 and $576.31 \mathrm{eV}$ all represent the binding energies of $\mathrm{Cr}(\mathrm{III}) 2 \mathrm{p},{ }^{55}$ which also show that the dangerous hexavalent $\mathrm{Cr}$ is almost non-existent in the prepared adsorbent. The $\mathrm{C}$ and $\mathrm{D}$ graphs have shown that the XPS spectra of PBC-800 C 1s and O 1s are composed of three peaks, respectively. The peaks are located at 289.1, 286.1, 284.5, $283.8,533.2,531.4$, and $529.4 \mathrm{eV}$, which are attributed to the carbon-oxygen double $(\mathrm{C}=\mathrm{O})$ bond, carbon-oxygen $(\mathrm{C}-\mathrm{O}) /$ carbon nitrogen $(\mathrm{C}-\mathrm{N})$ bond, carbon-carbon $(\mathrm{C}=\mathrm{C})$ double bond, carbon-carbon (C-C)/carbon-hydrogen (C-H) bond, $\mathrm{Cr}(\mathrm{III})$ organic oxygen, $\mathrm{Cr}$ deficient oxygen $(\mathrm{Cr}-\mathrm{O}) /$ oxygen hydrogen $(\mathrm{O}-\mathrm{H})$ bond and lattice oxygen in the metal oxide $(\mathrm{Cr}-\mathrm{O})^{43,55,56}$

The FTIR spectrum of PBC-800 is presented in Fig. 6(G). The strong band at $3428 \mathrm{~cm}^{-1}$ represents the $\mathrm{O}-\mathrm{H}$ stretching vibration. The band at $2853-2943 \mathrm{~cm}^{-1}$ is attributed to the $\mathrm{C}-\mathrm{H}$ symmetric asymmetric stretching vibration. The bands at 1735$1623 \mathrm{~cm}^{-1}$ and $1500-1384 \mathrm{~cm}^{-1}$ are assigned to $\mathrm{C}=\mathrm{O}$ and $\mathrm{C}-\mathrm{C}$ tensile vibrations, respectively. The belt at $1250-1136 \mathrm{~cm}^{-1}$ corresponds to the $\mathrm{C}-\mathrm{O}$ stretching vibration. ${ }^{30} \mathrm{~A}$ series of bands recorded in the $750-500 \mathrm{~cm}^{-1}$ region are attributed to vibrations of $\mathrm{C}=\mathrm{C} .{ }^{30}$ Therefore, combining the results from XPS and FTIR, it was found that PBC-800 contains carboxyl groups, amino groups, hydroxyl groups and metal oxides to facilitate the adsorption of TC.

\subsection{Adsorption mechanism}

The thermogravimetric curves and infrared spectra of PBC-800 and PBC-800-loaded (loaded means PBC-800 after adsorption of TC) are shown in Fig. 6(F and G). The weight loss below $100{ }^{\circ} \mathrm{C}$ represents dehydration. Because TC occupied most of 
the special sites, resulting in less water being adsorbed by PBC800 , the mass percentage of PBC-800-loaded TC dehydration was less than PBC-800. At $500-600{ }^{\circ} \mathrm{C}$, the PBC-800-loaded weight loss percentage and rate were faster as compared to PBC-800, which may be because the adsorbed TC decomposed together with the unstable components in the PBC-800. TC $\left(\mathrm{C}_{22} \mathrm{H}_{24} \mathrm{~N}_{2} \mathrm{O}_{8}\right)$ contains a large amount of $\mathrm{C}$. As a result, the total weight loss of the PBC-800-loaded sample was less as compared to PBC-800. The above phenomena indicate that TC was steadily bonded on PBC-800.

The TC structures of different ion states are shown in Fig. S5. $\uparrow$ Since the ketone group has strong electronwithdrawing ability, the conjugated ketene structure of TC affects its own $\pi$-electron acceptor properties and easily forms a $\pi-\pi$ EDA interaction with BC. ${ }^{40}$ For example, cationic $\pi$ bond interactions can occur due to the protonation of the amino group on the carbocyclic ring. ${ }^{57}$ In the FTIR spectrum (Fig. 5G), the $\mathrm{PBC}-800$-loaded $\mathrm{C}=\mathrm{C}$ is represented by a single peak, and the intensity is greatly weakened; the $\mathrm{C}-\mathrm{C}$ peak shape is obvious, and the intensity is increased. Thus, PBC-800 adsorption of TC can be achieved by forming $\pi-\pi$ EDA. In addition, it is well known that the phenolic hydroxyl, amine, hydroxyl and ketene moieties of TC can form HB with carboxyl and hydroxyl functional groups. ${ }^{40}$ Because the zeta potential of PBC-800 is negative, protonated amino groups are also most susceptible to EA. According to the results of this experiment, CB and SC are prone to occur on the surface of the metal, especially under alkaline conditions. According to XPS analysis, after the adsorption of TC on PBC-800, the peak of $\mathrm{Cr} 2 \mathrm{p}$ changed from $585.89 \mathrm{eV}$ (virgin adsorbent) to $586.42 \mathrm{eV}$, and the peak of $\mathrm{Cr} 2 \mathrm{p}$ slightly shifted up by 0.58 to 576.13 and $576.71 \mathrm{eV}$. The increase in the binding energy of $\mathrm{Cr}$ indicated the decrease in the electron density due to the formation of $\mathrm{Cr}-\mathrm{O}$ bonds between $\mathrm{Cr}$ and TC through complexation and cation bridges during the adsorption process. ${ }^{43}$

Fig. 7 provides a schematic illustration of the mechanism, the foremost mechanism of PBC-800 adsorption of TC is as follows. ${ }^{40}$ Although adsorption involves a small part of physical adsorption (van der Waals forces), chemical adsorption dominates. Under acidic conditions, TC is easily combined with PBC800 through $\mathrm{HB}$ and $\mathrm{SC}$, and protonated amino and $\mathrm{C}=\mathrm{C}$ can cause electron transfer. Under neutral pH conditions, the most likely reaction is that the tetracycline molecule is electrostatically attracted to the protonated amino group and the phenolic hydroxyl group on the PBC-800. As the basicity of the system increases, the main interaction of TC and PBC-800 is CB and SC.

\section{Conclusion}

PBC-800 has a graphitized porous structure with SSA as high as $2010.4 \mathrm{~m}^{2} \mathrm{~g}^{-1}$ and an average pore diameter of $2.8 \mathrm{~nm}$. The raw material contains a tightly bound trivalent $\mathrm{Cr}$, which plays an active role in the carbon formation stage and adsorption process. PBC-800 not only contains a plurality of oxygencontaining functional groups but also has special metal sites. By using equation fitting, experimental data and characterization methods, it has been proved that PBC- 800 adsorption of TC is a chemical reaction ( $\mathrm{HB}, \mathrm{SC}, \pi-\pi \mathrm{EDA}$, EA and $\mathrm{CB}$ ) process and the maximum adsorption capacity can reach $593.84 \mathrm{mg} \mathrm{g}^{-1}$ (Langmuir). Anion effect experiments with different ionic strengths indicate that the inhibitory impact of dianions on adsorption is significantly stronger as compared to monovalent anions. Different anion types have different effects on adsorption, which is helpful for understanding the adsorption behavior in actual water bodies. The total release of $\mathrm{Cr}$ is below $0.05 \mathrm{mg} \mathrm{L}^{-1}$, which means that the adsorbent is stable and will not cause serious secondary pollution; this opens up the possibility for engineering applications of PBC-800.

\section{Conflicts of interest}

There are no conflicts to declare.

\section{Acknowledgements}

The authors would like to acknowledge the financial support from the National Natural Science Foundation of China (No. 21808146 and No. 51878423).

\section{References}

1 L. Wollenberger, B. Halling-Sørensen and K. O. Kusk, Chemosphere, 2000, 40, 723-730.

2 M.-L. Loke, J. Tjørnelund and B. Halling-Sørensen, Chemosphere, 2002, 48, 351-361.

3 K. Kümmerer, Chemosphere, 2009, 75, 417-434.

4 L. B. Massey, B. E. Haggard, J. M. Galloway, K. A. Loftin, M. T. Meyer and W. R. Green, Ecol. Eng., 2010, 36, 930-938.

5 Y. Valcárcel, S. González Alonso, J. L. Rodríguez-Gil, A. Gil and M. Catalá, Chemosphere, 2011, 84, 1336-1348.

6 D. G. J. Larsson, C. de Pedro and N. Paxeus, J. Hazard. Mater., 2007, 148, 751-755.

7 O. A. Arikan, L. J. Sikora, W. Mulbry, S. U. Khan, C. Rice and G. D. Foster, Process Biochem., 2006, 41, 1637-1643.

8 N. Esiobu, L. Armenta and J. Ike, Int. J. Environ. Health Res., 2002, 12, 133-144.

9 A. K. Sarmah, M. T. Meyer and A. B. A. Boxall, Chemosphere, 2006, 65, 725-759.

10 H. Xiong, S. Dong, J. Zhang, D. Zhou and B. E. Rittmann, Water Res., 2018, 136, 75-83.

11 H. Zhang, Q. Ji, L. Lai, G. Yao and B. Lai, Chin. Chem. Lett., 2019, 30, 1129-1132.

12 W. Sun, Y. Sun, K. J. Shah, P.-C. Chiang and H. Zheng, J. Hazard. Mater., 2018, 370, 24-32.

13 J. Li, Y. Li, Z. Xiong, G. Yao and B. Lai, Chin. Chem. Lett., 2019, DOI: 10.1016/j.cclet.2019.04.057.

14 S. Shao, Y. Hu, C. Cheng, J. Cheng and Y. Chen, Chemosphere, 2018, 209, 35-43.

15 L. Ji, Y. Wan, S. Zheng and D. Zhu, Environ. Sci. Technol., 2011, 45, 5580-5586.

16 J. Cao, L. Lai, B. Lai, G. Yao, X. Chen and L. Song, Chem. Eng. J., 2019, 364, 45-56.

17 J. Cao, Z. Xiong and B. Lai, Chem. Eng. J., 2018, 343, 492-499. 
18 M. W. I. Schmidt and A. G. Noack, Global Biogeochem. Cycles, 2000, 14, 777-793.

19 C. Ma, H. Huang, X. Gao, T. Wang, Z. Zhu, P. Huo, Y. Liu and Y. Yan, J. Taiwan Inst. Chem. Eng., 2018, 91, 299-308.

20 T. Chen, L. Luo, S. Deng, G. Shi, S. Zhang, Y. Zhang, O. Deng, L. Wang, J. Zhang and L. Wei, Bioresour. Technol., 2018, 267, 431-437.

21 Y. Zhou, X. Liu, Y. Xiang, P. Wang, J. Zhang, F. Zhang, J. Wei, L. Luo, M. Lei and L. Tang, Bioresour. Technol., 2017, 245, 266-273.

22 H. Li, J. Hu, Y. Meng, J. Su and X. Wang, Sci. Total Environ., 2017, 603-604, 39-48.

23 L. Tang, J. Yu, Y. Pang, G. Zeng, Y. Deng, J. Wang, X. Ren, S. Ye, B. Peng and H. Feng, Chem. Eng. J., 2018, 336, 160-169.

24 L. Dai, W. Zhu, L. He, F. Tan, N. Zhu, Q. Zhou, M. He and G. Hu, Bioresour. Technol., 2018, 267, 510-516.

25 M. A. Zazycki, M. Godinho, D. Perondi, E. L. Foletto, G. C. Collazzo and G. L. Dotto, J. Cleaner Prod., 2018, 171, 57-65.

26 L. C. A. Oliveira, C. V. Z. Coura, I. R. Guimarães and M. Gonçalves, J. Hazard. Mater., 2011, 192, 1094-1099.

27 I. C. Kantarli and J. Yanik, J. Hazard. Mater., 2010, 179, 348356.

28 K. J. Sreeram, S. Saravanabhavan, J. R. Rao and B. U. Nair, Ind. Eng. Chem. Res., 2004, 43, 5310-5317.

29 N. Konikkara, L. J. Kennedy and J. J. Vijaya, J. Hazard. Mater., 2016, 318, 173-185.

30 A. C. Martins, O. Pezoti, A. L. Cazetta, K. C. Bedin, D. A. S. Yamazaki, G. F. G. Bandoch, T. Asefa, J. V. Visentainer and V. C. Almeida, Chem. Eng. J., 2015, 260, 291-299.

31 J. Wang and S. Kaskel, J. Mater. Chem., 2012, 22, 2371023725.

32 W.-J. Liu, H. Jiang and H.-Q. Yu, Chem. Rev., 2015, 115, 12251-12285.

33 H. M. Jang, S. Yoo, Y.-K. Choi, S. Park and E. Kan, Bioresour. Technol., 2018, 259, 24-31.

34 M. Taheran, M. Naghdi, S. K. Brar, E. J. Knystautas, M. Verma, A. A. Ramirez, R. Y. Surampalli and J. R. Valero, Sci. Total Environ., 2016, 571, 772-777.

35 Y. Wang, S. Gao, X. Zang, J. Li and J. Ma, Anal. Chim. Acta, 2012, 716, 112-118.

36 I. Made Joni, M. Vanitha, P. Camellia and N. Balasubramanian, Diamond Relat. Mater., 2018, 88, 129136.
37 A. C. Ferrari and D. M. Basko, Nat. Nanotechnol., 2013, 8, 235. 38 K.-T. Wu, P.-H. Wu, F.-C. Wu, R.-L. Jreng and R.-S. Juang, Chem. Eng. J., 2013, 221, 373-381.

39 A. B. Albadarin, M. N. Collins, M. Naushad, S. Shirazian, G. Walker and C. Mangwandi, Chem. Eng. J., 2017, 307, 264-272.

40 C. Peiris, S. R. Gunatilake, T. E. Mlsna, D. Mohan and M. Vithanage, Bioresour. Technol., 2017, 246, 150-159.

41 Y. Zhou, X. Liu, L. Tang, F. Zhang, G. Zeng, X. Peng, L. Luo, Y. Deng, Y. Pang and J. Zhang, J. Hazard. Mater., 2017, 333, 80-87.

42 E. Molis, O. Barrès, H. Marchand, E. Sauzéat, B. Humbert and F. Thomas, Colloids Surf., A, 2000, 163, 283-292.

43 Q. Liu, L.-B. Zhong, Q.-B. Zhao, C. Frear and Y.-M. Zheng, ACS Appl. Mater. Interfaces, 2015, 7, 14573-14583.

44 D. Reichenberg, J. Am. Chem. Soc., 1953, 75, 589-597.

45 R. A. Figueroa, A. Leonard and A. A. MacKay, Environ. Sci. Technol., 2004, 38, 476-483.

46 R. A. Figueroa and A. A. MacKay, Environ. Sci. Technol., 2005, 39, 6664-6671.

47 S. A. Sassman and L. S. Lee, Environ. Sci. Technol., 2005, 39, 7452-7459.

48 S. R. Martin, Biophys. Chem., 1979, 10, 319-326.

49 L. A. Mitscher, Arch. Pharm., 1978, 312, 719.

50 H. C. Wells, K. H. Sizeland, R. L. Edmonds, W. Aitkenhead, P. Kappen, C. Glover, B. Johannessen and R. G. Haverkamp, ACS Sustainable Chem. Eng., 2014, 2, 1864-1870.

51 N. Le-Minh, S. J. Khan, J. E. Drewes and R. M. Stuetz, Water Res., 2010, 44, 4295-4323.

52 G. Ersan, O. G. Apul, F. Perreault and T. Karanfil, Water Res., 2017, 126, 385-398.

53 Y. Zhou, O. G. Apul and T. Karanfil, Water Res., 2015, 79, 5767.

54 J. Rivera-Utrilla, C. V. Gómez-Pacheco, M. Sánchez-Polo, J. J. López-Peñalver and R. Ocampo-Pérez, J. Environ. Manage., 2013, 131, 16-24.

55 M. C. Biesinger, B. P. Payne, A. P. Grosvenor, L. W. M. Lau, A. R. Gerson and R. S. C. Smart, Appl. Surf. Sci., 2011, 257, 2717-2730.

56 S. Yang, S. Wang, X. Liu and L. Li, Carbon, 2019, 147, 540549.

57 L. Ji, W. Chen, L. Duan and D. Zhu, Environ. Sci. Technol., 2009, 43, 2322-2327. 